\title{
The effects of 1,4-dimethylpyridine in metastatic prostate cancer in mice
}

\author{
Agnieszka Denslow', Marta Switalska', Marcin Nowak², Magdalena Maciejewska', Stefan Chlopicki, \\ Andrzej Marcinek ${ }^{5}$, Jerzy Gebicki ${ }^{5}$ and Joanna Wietrzyk ${ }^{1 *}$
}

\begin{abstract}
Background: We previously showed that 1-methylnicotinamide (1-MNA) and its analog 1,4-dimethylpyridine (1,4-DMP) could inhibit the formation of lung metastases and enhance the efficacy of cyclophosphamide-based chemotherapy in the model of spontaneously metastasizing 4T1 mouse mammary gland tumors. In the present study, we aimed to investigate whether the previously observed activity of pyridine compounds pertains also to the prevention and the treatment of metastatic prostate tumors, in a combined chemotherapy with docetaxel.

Methods: Cancer-preventing activity of 1,4-DMP was studied in the model of prostate tumors spontaneously arising in C57BL/6-Tg (TRAMP)8247Ng/J (TRAMP) mice. The efficacy of the combined chemotherapy, comprising simultaneous use of 1,4-DMP and docetaxel, was evaluated in the orthotopic mouse model of human PC-3M-luc2 prostate cancer. The toxicity of the applied treatment was also determined.

Results: The development of prostate tumors in TRAMP mice remained unaffected after administration of 1,4-DMP. Similarly, no effect of 1,4-DMP was found on the growth of orthotopically transplanted PC-3M-luc2 tumors. However, when 1,4-DMP was administered along with docetaxel, it enhanced the anticancer activity of the chemotherapy. As a result, in PC-3M-luc2-bearing mice statistically significant inhibition of the tumor growth and lower metastases incidence were observed. The decreased metastatic yield is probably related to the diminished platelet activity observed in mice treated with combined therapeutic regimen. Finally, the combined treatment exhibited lowered side effects accompanying docetaxel administration.
\end{abstract}

Conclusions: Results presented herein confirm previously published data on the anticancer activity of pyridine compounds and demonstrate that 1,4-DMP may be beneficially implemented into chemotherapy utilizing various cytotoxic agents, directed against multiple metastatic tumor types.

Keywords: Prostate cancer, Metastasis, Prevention, Combined therapy, 1-methylnicotinamide, 1,4-dimethylpyridine, Docetaxel

\section{Background}

Prostate cancer is the second most common cancer of men, affecting approximately $14 \%$ of patients [1]. While the risk of developing prostate cancer might be beneficially influenced by proper diet and physical activity [2], there are no confirmed pharmacological means for the prevention of these types of tumors. The majority of prostate cancer cases are diagnosed at the localized stage enabling effective treatment; however, a significant fraction of patients develops

\footnotetext{
*Correspondence: wietrzyk@iitd.pan.wroc.pl

'Hirszfeld Institute of Immunology and Experimental Therapy, Polish

Academy of Sciences, Weigla 12, Wroclaw 53-114, Poland

Full list of author information is available at the end of the article
}

metastatic disease that often progresses into treatmentirresponsive, ultimately resulting in patient's death [3].

Initial treatment of prostate cancer usually comprises hormone therapy; however, when tumors are irresponsive to hormonal treatment (i.e., in case of castrateresistant prostate cancer), the most common first-line treatment includes the simultaneous use of docetaxel and prednisone. Docetaxel is a semi-synthetic taxane that inhibits microtubular depolymerization and block $b c l-2$ and $b c l-x l$ gene expression $[4,5]$. Prednisone, in turn, is a glucocorticoid that is used to improve symptoms such as pain [6]. It was also shown to inhibit cell proliferation and induce apoptosis in prostate cancer 
cells $[7,8]$, and thus decrease the level of prostatespecific antigen [9]. Accordingly, in multiple studies, prednisone was shown to promote anticancer activity of docetaxel [10-14]. However, the use of glucocorticosteroids in patients with prostate cancer is associated with the risk of adverse side effects (as reviewed, for example, by Dorff and Crowford [15]), and it eventually leads to the development of resistance to chemotherapy [16]. Therefore, there is still an urgent need for new treatment regimens that would enable efficient yet safe means for the therapy of patients suffering from prostate cancer.

1-methylnicotinamide (1-MNA) is an endogenous metabolite of nicotinamide (NA) that has recently gained attention due to its anti-inflammatory [17] and antithrombotic [18] activity driven by mechanisms dependent on prostacyclin $\left(\mathrm{PGI}_{2}\right)$ release $[18,19]$. Another compound that has been shown to modulate thrombus formation based on the $\mathrm{PGI}_{2}$-related mechanisms is 1,4dimethylpyridine (1,4-DMP) - a structural analog of 1MNA that arises naturally in roasted coffee seeds [20]. In addition, it has been recently shown that both 1-MNA and 1,4-DMP could inhibit metastases formation in the model of experimental and spontaneous metastasis of $4 \mathrm{~T} 1$ murine mammary gland cancer [21].

The present work is aimed to establish whether 1,4DMP may have an anti-oncogenic effect in the prophylaxis and the treatment of prostate tumors.

\section{Methods}

\section{Drugs}

1,4-DMP and 1-MNA were used in the form of chlorides provided by the Institute of Applied Radiation Chemistry, Technical University of Lodz, Poland. Prior to use, both salts were diluted in drinking water such that mice received the predetermined dose of the drugs. Docetaxel (DTX) was purchased at Ak Scientific (USA). All drugs were administrated at the doses and according to the schedules presented in Table 1.

\section{Mice}

Eight- to twelve-weeks-old male C57BL/6-Tg(TRAMP) $8247 \mathrm{Ng} / \mathrm{J}$ (TRAMP) mice were purchased from the Jackson Laboratory (USA). Seven- to eight-weeks-old
BALB/c Nude male mice were provided by Charles Rivers Laboratories (Germany) (Table 2). All experiments were performed according to the Interdisciplinary Principles and Guidelines for the Use of Animals in Research, Marketing and Education issued by the New York Academy of Sciences' Ad Hoc Committee on Animal Research and were approved by the 1st Local Committee for Experiments with the Use of Laboratory Animals, Wroclaw, Poland.

\section{Cell culture and transplantation}

Human prostate cancer PC-3M-luc2 cell line stably expressing the firefly luciferase gene $(l u c)$ was obtained from Caliper Life Sciences Inc. (USA). Cells were cultured in RPMI 1640 + Gluta-MAX ${ }^{\mathrm{Tm}}$ medium (Life Technologies, USA) supplemented with $10 \%$ fetal bovine serum (Sigma-Aldrich, Germany) and antibiotics (penicillin and streptomycin-Polfa Tarchomin, Poland). Cell line cultures were maintained at $37{ }^{\circ} \mathrm{C}$ in a humidified atmosphere with $5 \% \mathrm{CO}_{2}$.

Prior to the transplantation, cells were trypsinized (IIET, Poland), centrifuged $\left(200 \times \mathrm{g}, 4{ }^{\circ} \mathrm{C}, 5 \mathrm{~min}\right)$ and counted. Then, cells were resuspended in Hank's Balanced Salt Solution (HBSS; IIET, Poland).

Male BALB/c Nude mice were intraperitoneally injected with ketamine at a dose of $50 \mathrm{mg} / \mathrm{kg}$ (VET-AGRO Sp. z o.o., Poland) and anesthetized with the mixture of air and isoflurane $(3 \% \mathrm{v} / \mathrm{v}) .1 .0 \mathrm{~cm}$ wide abdominal wall incision was made just above the bladder, in the lower part of abdomen, and the prostate gland was exposed for the injection. Then, $5 \times 10^{6}$ PC-3M-luc2 cells in $0.05 \mathrm{ml}$ of HBSS were inoculated into the dorsal prostate lobes of mice. Immediately after the transplantation, incised abdominal wall and skin were sewed with soluble surgical suture.

\section{Estimation of the antitumor activity}

The development of prostate tumors in TRAMP mice was monitored weekly by physical examination. Adenocarcinoma formation was confirmed by histological examination of the tumors isolated from mice during necropsy carried out in animals with clear physiological (e.g., body weight or body temperature decrease, body posture, ruffled fur) and behavioral symptoms (e.g., decreased movement) of an advanced disease. Briefly,

Table 1 Drugs, doses and therapeutic regimens applied in the presented studies

\begin{tabular}{|c|c|c|c|c|}
\hline Experimental model & Drug & Route of administration & Dose & Treatment regimen \\
\hline \multirow[t]{2}{*}{$\begin{array}{l}\text { Spontaneous tumor } \\
\text { formation (Fig. 1) }\end{array}$} & 1-MNA & per os in drinking water & $100 \mathrm{mg} / \mathrm{kg} / \mathrm{day}$ & $\begin{array}{l}\text { continuously from the age of } 8 \text { to } 12 \text { weeks } \\
\text { to the day of the necropsy }\end{array}$ \\
\hline & 1,4-DMP & per os in drinking water & $100 \mathrm{mg} / \mathrm{kg} /$ day & $\begin{array}{l}\text { continuously from the age of } 8 \text { to } 12 \text { weeks } \\
\text { to the day of the necropsy }\end{array}$ \\
\hline \multirow[t]{2}{*}{$\begin{array}{l}\text { PC-3 M-luc2 tumors } \\
\text { (Fig. 2) }\end{array}$} & 1,4-DMP & per os in drinking water & $100 \mathrm{mg} / \mathrm{kg} /$ day & $\begin{array}{l}\text { continuously from the day } 1 \text { to the end } \\
\text { of the experiment }\end{array}$ \\
\hline & DTX & intraperitoneally & 10 mg/kg & 2 doses at days 15 and 22 \\
\hline
\end{tabular}


Table 2 Strains and number of mice used in the experiments

\begin{tabular}{llll}
\hline Experimental model & $\begin{array}{l}\text { Mouse } \\
\text { strain }\end{array}$ & $\begin{array}{l}\text { No of mice/ } \\
\text { group }\end{array}$ & $\begin{array}{l}\text { Total No of } \\
\text { used mice }\end{array}$ \\
\hline $\begin{array}{l}\text { Spontaneous tumor } \\
\text { formation (Fig. 1) }\end{array}$ & TRAMP & 15 & 45 \\
$\begin{array}{l}\text { PC-3M-luc2 tumors } \\
\text { (Figs. 2, 3 and 4) }\end{array}$ & C57BL/6 & 9 & 36 \\
\hline
\end{tabular}

prostate tumors were isolated and fixed in buffered formalin, and then cut into 4- $\mu$ m-thick sections that were subsequently dewaxed with xylene. Following rehydration in a gradient of ethanol, the sections were washed in distilled water, cytoplasm was stained with eosin while nuclei were counterstained in hematoxylin. Finally, the preparations were dehydrated in an alcohol gradient and coverslip mounted. The histological appearance of the tissue was examined at $50 \times$ or $100 \times$ magnitude.

Using an In vivo MS FX PRO system (Carestream Health INC., USA), in vivo visualizations of PC-3 Mluc2 tumors growing in prostate gland of BALB/c Nude mice were performed no more often than every 4 days starting from the 15th day of the experiment. In brief, about $10 \mathrm{~min}$ before imaging, D-luciferin potassium salt (Synchem INC., Germany) was administered to each mouse intraperitoneally at a dose of $150 \mathrm{mg} / \mathrm{kg}$. Then, animals were anesthetized with a $3-5 \%(\mathrm{v} / \mathrm{v})$ mixture of isoflurane (Forane, Abbott Laboratories, USA) in synthetic air $(200 \mathrm{ml} / \mathrm{min})$. Anesthesia was maintained with $1.5-2 \%(\mathrm{v} / \mathrm{v})$ mixture of isoflurane and synthetic air delivered via individual masks. Visualization was carried out using the following settings: for $\mathrm{X}$-ray $-\mathrm{t}=2 \mathrm{~min}$, $\mathrm{f}$-stop $=5.57, \mathrm{FOV}=198.6$; for luminescence capture $-\mathrm{t}$ $=3$ min, binning $2 \times 2$, f-stop $=5.57, \mathrm{FOV}=198.6$. Images were analyzed with Carestream MI SE software (Carestream Health INC., USA). The intensity of the luminescent signal is presented as the sum intensity of the region of interest and expressed in arbitrary units (a.u.). Tumor tissue was also excised and weighted on the last day of the experiment (day 46).

\section{Evaluation of the antimetastatic effect}

Livers, lungs, kidneys, bones and axillary as well as inguinal lymph nodes were isolated and fixed in buffered formalin on the day of the necropsy, in order to detect metastases in the mice bearing prostate tumors. Then, tissue samples were cut into 4 - $\mu$ m-thick sections and stained as described hereinabove. The number of metastases in isolated tissues was counted at $50 \times$ or $400 \times$ magnitude.

\section{Platelet activation status}

Blood samples were collected on days 87, 122, 213 and during animal's necropsy in the model of the spontaneously formed prostate tumors or on the last day of the experiment (day 46) in case of mice bearing PC-3M-luc2 tumors. Samples were collected in tubes containing $0.05 \mathrm{ml}$ of $5 \%$ ethylenediaminetetraacetic acid (EDTA) solution (Sigma-Aldrich, Germany). Platelet-related morphology analyzes were performed using Mythic 18 analyzer (C2 Diagnostics, France). Then, blood plasma was obtained by centrifugation $\left(2000 \times \mathrm{g}, 15 \mathrm{~min}, 4{ }^{\circ} \mathrm{C}\right)$ and stored at $-80{ }^{\circ} \mathrm{C}$ until further analyzes. Prostacyclin generation in the treated mice was determined by the quantification of plasma 6-keto-prostaglandin F1 $\alpha$ (6keto-PGF1 $\alpha$ ) levels. Based on thromboxane $\mathrm{B}_{2}\left(\mathrm{TXB}_{2}\right)$, von Willebrand factor (vWF) and soluble P-selectin plasma concentrations, platelet activation status was estimated. Using commercial kits available from Cusabio Biotech Co. Ltd. (Wuhan, China), all analyzes were conducted via the ELISA technique. In addition, plasma concentration of transforming growth factor $\beta 1$ (TGF$\beta 1$ ) was determined with ELISA kit from Boster Biological Technology (USA). All ELISA-based analyzes were conducted according to the manufacturer's instructions.

\section{Protein expression in tumor tissue}

Protein expression in prostate tumor tissue was analyzed according to the standard Western blot procedure [22]. In brief, using a FastPrep-24 MP Bio device (Mp Biomedicals LLC., USA), samples of tumor tissue that were collected and immediately frozen on the last day of the experiments were homogenized in RIPA Buffer (SigmaAldrich, Germany) with the following settings: CP $24 \times$ $2,6 \mathrm{~m} / \mathrm{s}, 40 \mathrm{~s}$. According to the manufacturer's protocol, protein content in all samples was analyzed using a BioRad Protein Assay (Bio-Rad Laboratories Inc., USA). Samples containing $100 \mu \mathrm{g}$ of protein were separated on the pre-cast 4-20\% gradient gels (Bio-Rad Laboratories, Inc., USA) and transferred onto $0.45 \mu \mathrm{m}$ polyvinylidene fluoride (PVDF) membranes (Merck Millipore, USA). Next, the membranes were probed with primary rabbit polyclonal anti-E-cadherin (1:1000), anti-N-cadherin (1:1000), anti-VEGFR-1 (1:200) antibodies (all from Proteintech Group, USA) or mouse anti- $\beta$-actin $(1: 1000$, Sigma-Aldrich, Germany) antibody. Finally, according to the manufacturer's instruction, the analyzed proteins were detected with IRDye ${ }^{\circ} 800 \mathrm{CW}$ Goat anti-Rabbit IgG or IRDye ${ }^{\circledast}$ 680RD Donkey anti-Mouse IgG (both from LI-COR, USA). Blots were visualized in ODDYSEY ${ }^{\oplus}$ CLx Imager (LI-COR, USA) and analyzed with ImageJ Software as follows. The total E-cadherin cellular content comprising truncated and unprocessed E-cadherin (with a molecular weight of approximately 100 and $130 \mathrm{kDa}$, respectively) was calculated. Similarly, total N-cadherin cellular content comprising mature and unprocessed $\mathrm{N}$ cadherin (with a molecular weight of approximately 70 and $100 \mathrm{kDa}$, respectively) was determined. Then, E- 
cadherin and $\mathrm{N}$-cadherin contents were normalized to $\beta$-actin. Finally, E-cadherin to $\mathrm{N}$-cadherin ratios in individual samples were calculated and presented as mean \pm $\mathrm{SD}$ values.

\section{Toxicity of the anticancer treatment}

The toxicity of the proposed anticancer treatment strategy and its influence on the overall health condition were estimated based on body weight changes as well as morphological and biochemical blood analyzes. The body weight of experimental animals was measured thrice each week throughout the course of all studies.

Blood morphology was performed with Mythic 18 analyzer (C2 Diagnostics, France). Using reagents and procedures provided by the manufacturer, biochemical analyzes were performed in Cobas C 111 analyzer (Roche Diagnostics, Switzerland).

\section{Statistical analysis}

Data normality was estimated using the Shapiro-Wilk test with a predetermined value of $p<0.05$. The TukeyKramer multiple comparison test for parametric data or the Kruskal-Wallis Test for non-parametric data was applied; $p$ values lower than 0.05 were considered significant. All calculations were performed using GraphPad Prism 7 (GraphPad Software, Inc., USA) software.

Unless stated otherwise, all data presented on graphs correspond to mean $\pm \mathrm{SD}$ values.

\section{Results}

The influence of 1,4-DMP on the onset and metastasis of spontaneously formed prostate tumors

To establish whether 1,4-DMP might prevent the development of prostate tumors, the compound was continuously given to male TRAMP mice that during their life span spontaneously develop mild intraepithelial hyperplasia to malignant neoplasia within prostate gland. For comparative purposes, another group of the animals was treated with 1-MNA, a primary analog of 1,4-DMP that was proven to possess significant antithrombotic and anti-inflammatory activity. 1-MNA, and to a lesser extent also 1,4-DMP, delayed the onset of prostate lesions in TRAMP mice (Fig. 1a). However, none of the given compounds prolonged the life span of treated animals (Fig. 1b). Histopathological analysis of the tumor tissues excised during the necropsy confirmed the development of malignant adenocarcinomas in approximately $80 \%$ of the mice in all experimental groups (Fig. 1c and d).

Histopathological analysis demonstrated that metastases in TRAMP mice prostate adenocarcinomas were developed in lymph nodes, lungs, liver and kidneys (Fig. 1d). Metastatic lesions were diagnosed in around $30 \%$ of untreated animals. Similarly, metastases were found in $30 \%$ of animals treated with 1,4-DMP. In contrast, when treated with 1 -MNA, $50 \%$ of mice developed metastases (Fig. 1c, not statistically significant difference).

The analysis of morphological features of blood platelets did not reveal changes in platelet mean volume and platelet distribution width (PDW) occurring during the study; however, we noted an increase in platelet count and decreased level of PDW in animals during the necropsy (Additional File: Figure S1c). The treatment either with 1-MNA or 1,4-DMP did not affect the platelet morphological parameters (Fig. 1eg, Additional File 1: Figure S1a-c). Similarly to platelets, red blood cell parameters also remained unaffected by the tumor progression, with an exception of the time preceding necropsy where a significant drop in red blood count was observed in all experimental groups. However, none of the studied compounds influenced the red blood cell parameters (Additional File 1: Figure S1d).

While there was no obvious change in the white blood cell count in TRAMP mice developing prostate tumors that was observed in the course of the study, we observed that 1,4-DMP and to a lesser extent 1MNA tended to decrease the number of all of lymphocytes, monocytes and granulocytes in the treated animals, when compared to the control group (Fig. 1h-j, Additional File 1: Figure S1e-g). This effect might be attributed to prostacyclin-dependent splenic dilation in the treated mice that leads to white blood cells pooling in the spleen, and in consequence, a systemic decrease in the white blood cell count [23]. The analysis of the biochemical parameters of platelet activity revealed no effect of the studied compounds on platelet activity in TRAMP mice (Fig. 1l-o). Finally, during the tumor development process, we observed that in TRAMP mice, the plasma level of TGF- $\beta 1$ was not affected either by 1,4-DMP or by 1-MNA (Additional File 1: Figure S1h).

\section{Anticancer activity of the combined treatment of prostate cancer comprising simultaneous application of 1,4-DMP and docetaxel}

The growth of primary tumors localized in prostate glands of BALB/c Nude mice was monitored throughout the experiment by in vivo imaging of the luminescence generated by PC-3M-luc2 cells. The analysis of the luminescence intensity indicated that 1,4-DMP when administered alone did not inhibit the growth of PC-3M-luc2 prostate tumors. On the contrary, marked tumor growth inhibition was observed when mice were treated with docetaxel alone or administered with 1,4-DMP (Fig. 2a and b). These observations were confirmed by the analysis of the tumor mass isolated from the mice on day 46 of the experiment. 


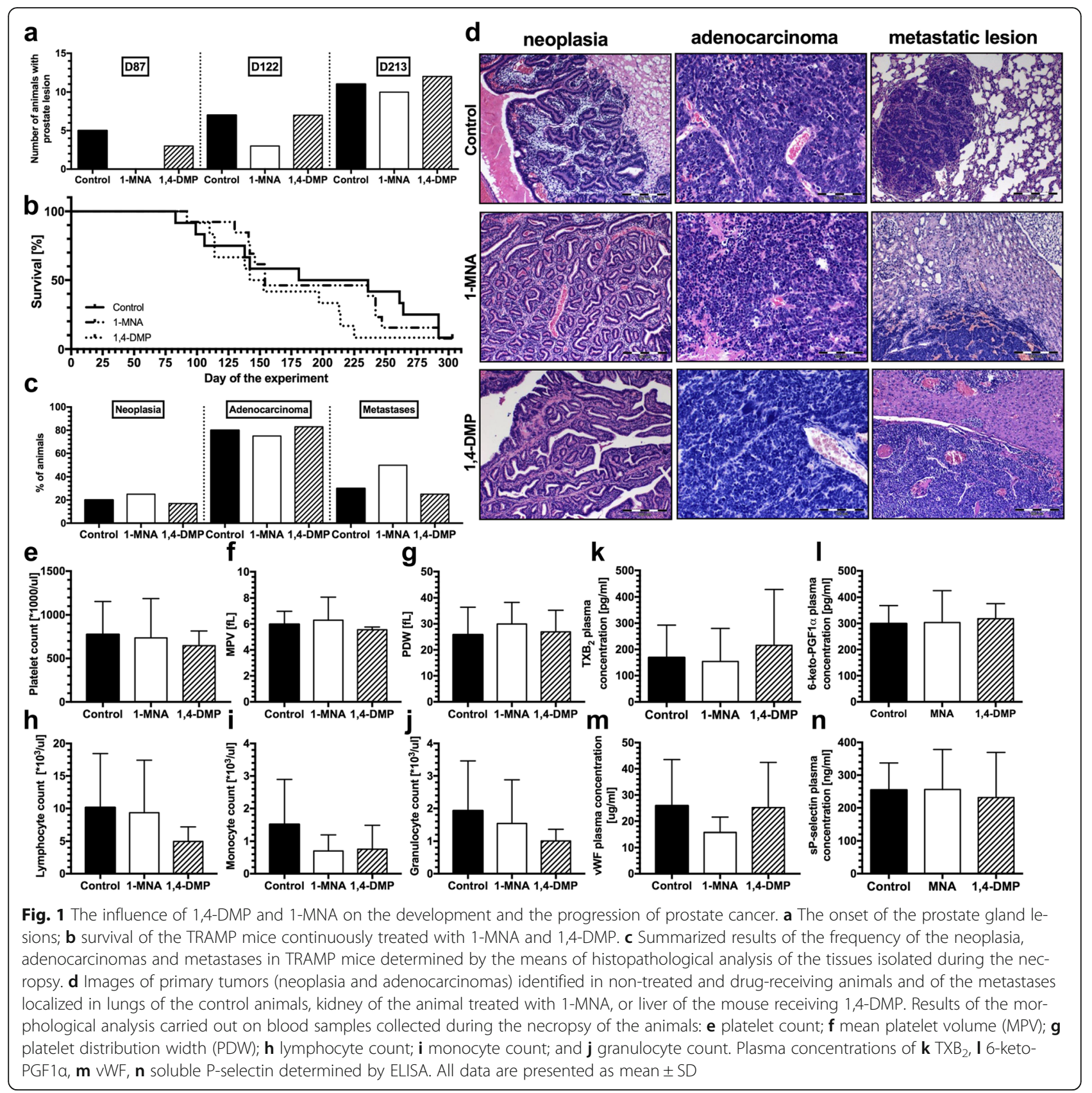

Docetaxel, when administered alone, inhibited the growth of PC-3M-luc2 tumors in around 50\% when compared to the control group of animals ( $0.40 \mathrm{~g}$ vs. $0.81 \mathrm{~g}$, respectively). Antitumor activity of docetaxel was additionally enhanced when the drug was administrated with 1,4-DMP and reached approx. $80 \%$ tumor growth inhibition $(0.17 \mathrm{~g}$ vs. $0.81 \mathrm{~g}, p<0.05$ ) (Fig. 2c).

Histopathological analysis of tissues collected from mice led to the identification of PC-3M-luc2 metastatic lesions in such tissues as lymph nodes, liver and lungs (Fig. 2d). We observed that the frequency of metastases formation in mice treated with 1,4-DMP decreased by almost $50 \%$.
Similarly, the number of metastases-bearing animals decreased in case of single-drug treatment with docetaxel. Most interestingly, none of the mice treated with 1,4-DMP and docetaxel developed PC-3M-luc2 metastases during the study (see Table 3).

We also decided to investigate the influence of applied treatment on the metastatic potential of tumorforming cancer cells. To this end, we evaluated the expression of E-cadherin, N-cadherin and vascular endothelial growth factor receptor 1 (VEGFR1) in tumor tissue. The results of the Western blot analysis show that 1,4-DMP had no significant effect on E- 


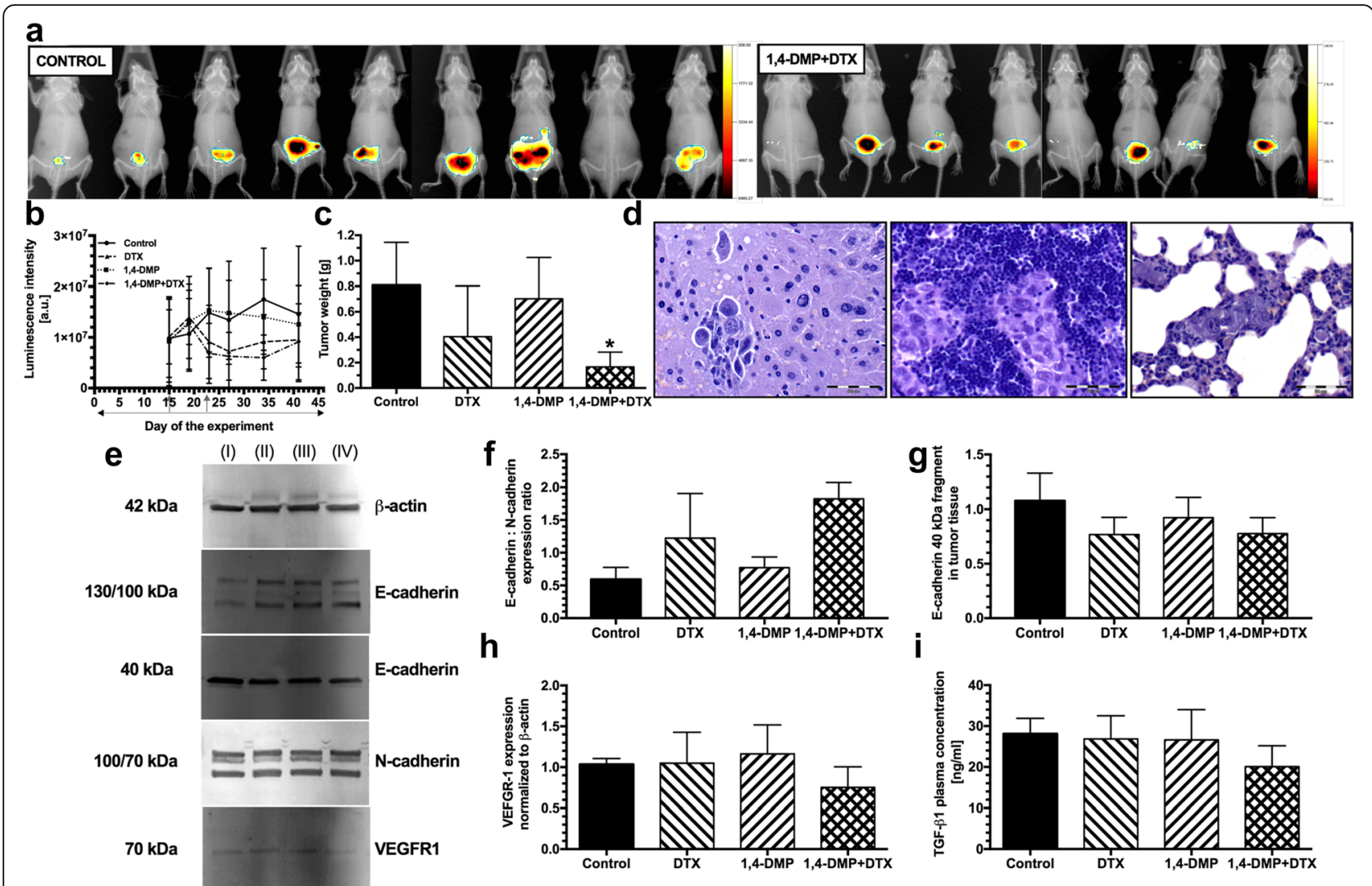

Fig. 2 Anticancer activity of the combined treatment comprising the use of docetaxel (DTX) and 1,4-DMP in the model of human prostate cancer PC-3M-luc2 xenografted into prostate glands of BALB/C Nude mice. a Results of in vivo imaging of PC-3M-luc2 tumors performed on day 41 of the experiment. $\mathbf{b}$ Kinetics of the PC-3M-luc2 tumor growth in mice treated with docetaxel (DTX) and 1,4-DMP given either alone and in a comparison to the control group of animals. Days of drug administration are indicated with gray arrows for docetaxel (DTX) and dotted arrow for 1,4-DMP. c PC-3M-luc2 tumor weight measured on the last day of the experiment (day 46) ( ${ }^{*} p<0.05$ vs. control and 1,4-DMP). $\mathbf{d}$ Images of metastases localized in liver of the control animal, lymph node of docetaxel (DTX)-treated mouse and lungs of the 1,4-DMP-treated mouse (from left to right). e Images of bands obtained during Western blot analysis of protein expression in tumor tissue of (I) control animals and animals treated with (II) docetaxel (DTX), (III) 1,4-DMP and (IV) docetaxel (DTX) with 1,4-DMP. f E-cadherin : N-cadherin expression ratios in the samples of tumor tissue collected on the last day of the experiment. The total cellular content of E-cadherin (comprising protein characterized by the molecular weight of 130 and $100 \mathrm{kDa}$ ) and $\mathrm{N}$-cadherin (comprising protein characterized by the molecular weight of 100 and $70 \mathrm{kDa}$ ) was first normalized to the content of $\beta$-actin and then used to determine $\mathrm{E}$-cadherin to $\mathrm{N}$-cadherin expression ratios. $\mathbf{g}$ The level of low molecular weight fragment of E-cadherin in PC-3M-luc2 tumors normalized to the content of $\beta$-actin. $\mathbf{h}$ The expression of VEGFR-1 in PC-3M-luc2 tumors normalized to the content of $\beta$-actin. i Plasma concentration of TGF- $\beta 1$ in mice bearing PC-3M-luc2 tumors. All data are presented as mean \pm SD values

Table 3 Frequency of metastases formation and localization of new lesions in mice bearing PC-3M-luc2 tumors

\begin{tabular}{lll}
\hline Treatment & $\begin{array}{l}\text { Animals with metastases/all } \\
\text { animals tested }\end{array}$ & Metastases location \\
\hline Control & $7 / 9$ & $\begin{array}{l}\text { Lungs, liver, lymph } \\
\text { nodes }\end{array}$ \\
1,4-DMP & $4 / 9$ & Lungs, liver \\
DTX & $1 / 6$ & Lymph nodes \\
1,4-DMP + & $0 / 8$ & - \\
DTX & & \\
\hline
\end{tabular}

cadherin to $\mathrm{N}$-cadherin expression ratio. In contrast, when mice were treated with docetaxel given alone, over twofold increase in E-cadherin to N-cadherin expression ratio was observed (not statistically significant). Such a phenomenon was additionally enhanced by simultaneous application of 1,4-DMP that allowed to reach over threefold enhancement of E-cadherin to $\mathrm{N}$-cadherin expression ratio (Fig. 2f). In addition, in PC-3M-luc2 tumor-bearing mice, we have observed the appearance of low molecular weight fragments of E-cadherin $(40 \mathrm{kDa})$. The concentration of these protein fragments was lowered in both groups treated with docetaxel, given either alone or with 1,4-DMP, while it was unaltered in mice receiving 1,4-DMP alone (Fig. 2g). The expression of VEGFR-1 was 
decreased in about 30\% in mice treated with combined therapy but was not affected either by docetaxel or by 1,4-DMP given alone (Fig. 2h).

Increased E-cadherin to $\mathrm{N}$-cadherin expression ratio was accompanied by the decreased plasma concentration of TGF $\beta-1$ in mice receiving the combined treatment consisting of docetaxel and 1,4-DMP (20.5 \pm $5.1 \mathrm{ng} / \mathrm{ml}$ vs. $28.13 \pm 3.7 \mathrm{ng} / \mathrm{ml}$ in the control group of mice, Fig. 2i).

The analysis of the morphological parameters of blood platelets revealed that while docetaxel given alone slightly lowered the platelet count, 1,4-DMP did not influence the platelet number when given alone but restored the number in docetaxel-treated animals (Fig. 3a and b). In addition, we observed that in animals receiving 1,4-DMP together with docetaxel, the mean platelet volume (MPV) and PDW were lowered when compared to the untreated animals $(6.02 \pm 0.4$ and $36.6 \pm 4.8$ vs. $6.42 \pm 0.4$ and $40.19 \pm 5.2 \mathrm{fL}$ in the control group of animals, Fig. $3 \mathrm{c}$ and d). In addition, when analyzing biochemical parameters of platelet activity, we observed that both docetaxel given alone as well as administered with 1,4-DMP significantly reduced plasma concentrations of $\mathrm{TXB}_{2}(49.18 \pm$ $24.0 \mathrm{pg} / \mathrm{ml}, 36.55 \pm 19.6 \mathrm{pg} / \mathrm{ml}$, respectively, vs. 147.4 $\pm 43.1 \mathrm{pg} / \mathrm{ml}$ in the control, $p<0.05)$, soluble $\mathrm{P}$ selectin $(158.3 \pm 46.3 \mathrm{ng} / \mathrm{ml}, \quad 157.6 \pm 36.7 \mathrm{ng} / \mathrm{ml}$, respectively, vs. $256 \pm 53.9 \mathrm{ng} / \mathrm{ml}$ in the control, $p<$ $0.05)$, and vWF $(2479 \pm 764 \mathrm{ng} / \mathrm{ml}, 2785 \pm 432 \mathrm{ng} / \mathrm{ml}$, respectively, vs. $4134 \pm 753 \mathrm{ng} / \mathrm{ml}$ in the control) (Fig. 3f-h). However, we also observed a significant drop in 6-keto-PGF1 $\alpha$ plasma concentration in mice treated with both docetaxel and 1,4-DMP (70.36 vs. $130.7 \mathrm{pg} / \mathrm{ml}, p<0.05$ ) (Fig. 3e).

\section{Toxicity of the combined treatment of prostate cancer} comprising simultaneous application of 1,4-DMP and docetaxel

In the control and 1,4-DMP-treated groups of animals, there were no cases of deaths recorded. On the contrary, administration of docetaxel resulted in 3 incidences of treatment-related deaths (effect was not statistically
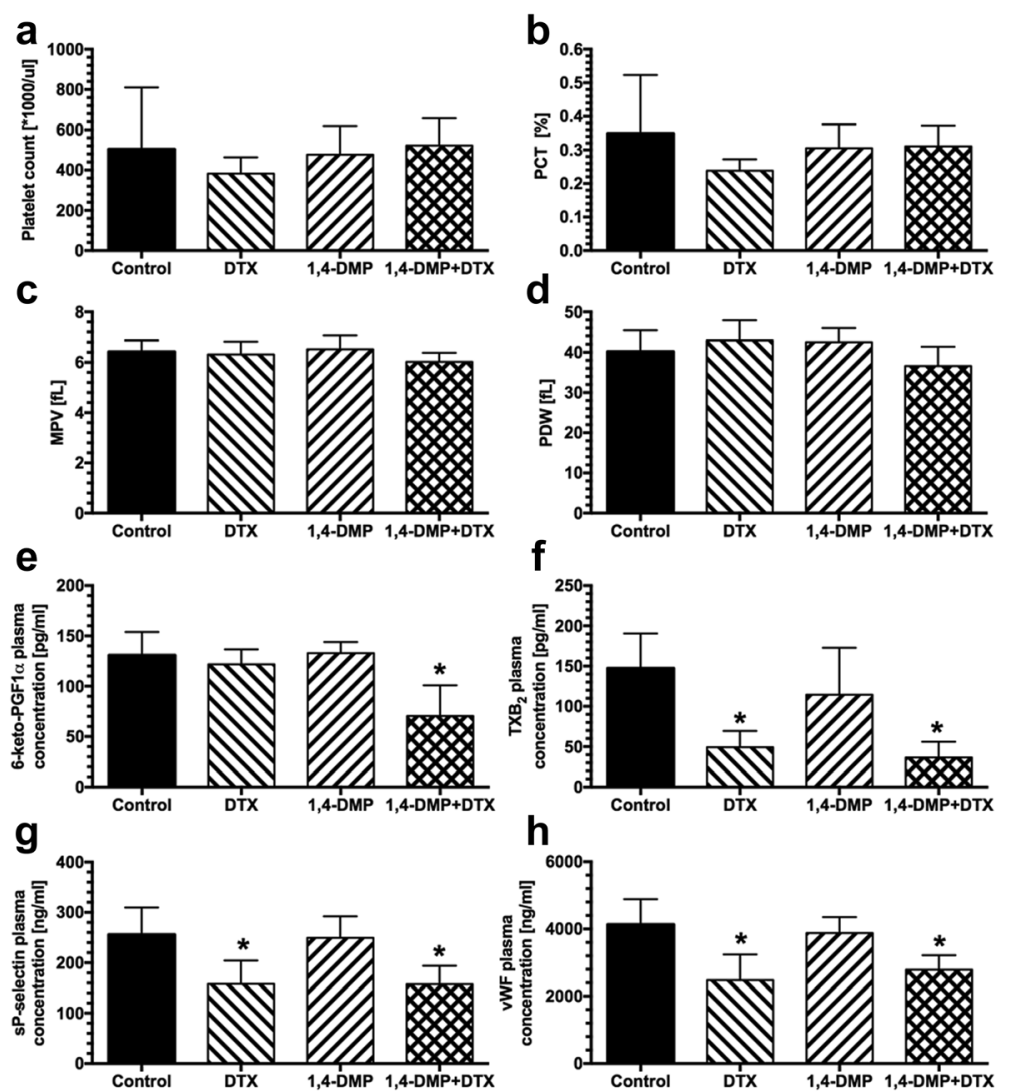

Fig. 3 The influence of the combined treatment comprising the use of docetaxel (DTX) and 1,4-DMP on platelet morphology and activity in BALB/C Nude mice bearing PC-3M-luc2 tumors. a Platelet count; b platelet crit (PCT); $\mathbf{c}$ mean platelet volume (MPV); $\mathbf{d}$ platelet distribution width (PDW) determined on the last day of the experiment (day 46). Plasma concentration of: e 6-keto-prostaglandin Fla (6-keto-PGF1a) $\left(^{*} p<0.05\right.$ vs. control and 1,4DMP); f thromboxane $B_{2}\left(T_{X B_{2}}\right)\left({ }^{*} p<0.05\right.$ vs. control and 1,4-DMP); $\mathbf{g}$ soluble P-selectin ( ${ }^{*} p<0.05$ vs. control and 1,4-DMP); and $\mathbf{h}$ von Willebrand Factor (VWF) ${ }^{*} p<0.05$ vs. control and 1,4-DMP), determined on the last day of the experiment (day 46). All data are presented as mean \pm SD values 
significant). Surprisingly, docetaxel-induced toxicity was lowered when cytotoxic drug was given simultaneously with 1,4-DMP. In case of animals treated with the combined regimen, only 1 incidence of death was recorded (Fig. 4a). Regardless of the treatment applied, the body weight of all tumor-bearing BALB/c Nude mice was decreasing throughout the study with the most prominent body loss observed among control and 1,4-DMP-treated animals (approx. 10-12\% body weight loss). Among the mice treated with docetaxel, a reduced body loss was observed (approx. 6\% body weight loss), which was nearly abolished among animals treated with the combined treatment (approx. 3\% body weight loss) (Fig. 4b).

The analysis of blood morphology of the treated animals revealed that similar to the platelet count described above, red blood cell count was lower in mice receiving docetaxel alone $\left(8.30 \pm 0.8 \times 10^{6}\right.$ vs. $\left.9.1 \pm 0.2 \times 10^{6}\right)$.
However, in contrast to platelet count, red blood cell count was not restored when docetaxel was administered simultaneously with 1,4-DMP $\left(8.4 \pm 0.6 \times 10^{6}\right)$ and corresponded to non-significant change in hemoglobin content that was observed in mice given docetaxel either alone or in combination with 1,4-DMP $(14.17 \pm 1.3 \mathrm{~g} / \mathrm{dl}$ and $14.34 \pm 0.9 \mathrm{~g} / \mathrm{dl}$ vs. $14.81 \pm 2.2 \mathrm{~g} / \mathrm{dl}$ in the control).

Blood biochemistry analysis revealed that in groups receiving docetaxel, levels of plasma concentrations for creatinine $(5.7 \pm 2.2$ vs. $7.59 \pm 2.3 \mu \mathrm{mol} / \mathrm{l}$ in the control) and urea $(6.98 \pm 1.3$ vs. $7.33 \pm 1.1 \mathrm{mmol} / \mathrm{l}$ in the control $)$ were not significantly changed. However, when docetaxel was concurrently administered with 1,4-DMP, it resulted in a significantly lowered creatinine $(4.99 \pm 1.5 \mu \mathrm{mol} / \mathrm{l}, p$ $<0.05$ vs. control and 1,4-DMP-treated group) and urea (5.67 $\pm 0.9 \mathrm{mmol} / \mathrm{l}, p<0.05$ vs. control and 1,4-DMPtreated group) concentrations (Fig. $4 \mathrm{e}-\mathrm{f}$ ).

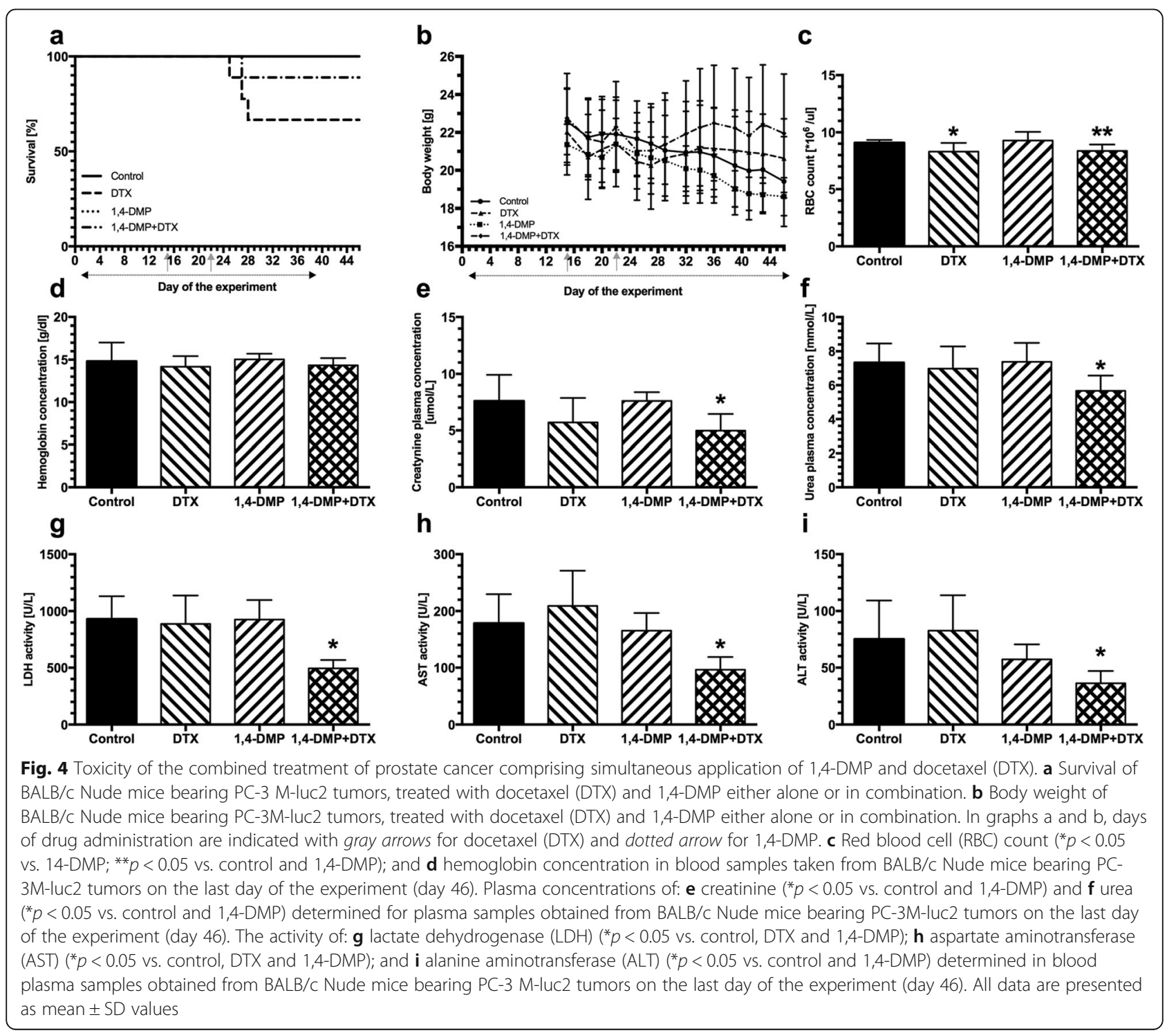


On the contrary, as it was determined for the blood plasma samples taken from the treated mice bearing PC3M-luc2 tumors, administration of docetaxel had no influence on the activity of lactate dehydrogenase (LDH) (887.1 \pm 251.5 vs. $929.6 \pm 202.5 \mathrm{U} / \mathrm{l}$ in the control, Fig. $4 \mathrm{~g}$ ) while resulted in a slightly increased activity of aspartate aminotransferase (AST) $(209.1 \pm 62.4$ vs. $178.3 \pm 51.7 \mathrm{U} / 1$ in the control) and alanine aminotransferase (ALT) $(82.72 \pm 31.8$ vs. $75.23 \pm 34.1 \mathrm{U} / \mathrm{l}$ in the control group) (Fig. $4 \mathrm{~h}$ and i). However, when docetaxel was given simultaneously with 1,4-DMP to mice, significantly lower activity of all studied liver enzymes was observed (LDH: $494.2 \pm 73.9 \mathrm{U} / \mathrm{l}$; AST: $96.36 \pm 22.6 \mathrm{U} / \mathrm{l}$; for both enzymes $p<0.05 \mathrm{vs}$. control, docetaxel and 1,4-DMP-treated group; ALT: $36.16 \pm 10.9 \mathrm{U} / \mathrm{l}$, $p<0.05$ vs. control and DTX-treated group) (Fig. 4g-i).

\section{Discussion}

1-MNA is an endogenous metabolite of NA that was previously shown to possess significant anti-inflammatory and anti-thrombotic activity $[17,18]$. 1-MNA is synthetized by nicotinamide $\mathrm{N}$-methyltransferase (NMMT), an enzyme expressed primarily in liver cells where it participates in methylation of NA and other pyridine compounds [24]. Concurrently, the expression of NMMT was reported in multiple types of cancer in which it was associated with tumor-promoting activity [25-27] that could be further attributed to 1-MNA [28]. On the contrary, some of the published reports show the beneficial correlation between NMMT expression and cancer survival $[29,30]$. Along the lines with such data in a recently published study, we have shown that exogenous 1-MNA does not enhance the growth of cancer cells neither in vitro nor in vivo but, in contrary, may possess antimetastatic activity, most likely resulting from its $\mathrm{PGI}_{2}$-releasing capacity. We have also shown that 1,4-DMP, a structural analog of 1-MNA, possesses similar antimetastatic activity; however, both compounds seemed to have different mechanisms of action that ultimately resulted in platelet-dependent metastasis inhibition. Importantly, pyridine compounds, but particularly 1,4-DMP, when given in a combination with cyclophosphamide contributed to its anticancer activity enhancing both antitumor and antimetastatic activity of cytostatic drug [21]. Referred studies were, however, carried out exclusively in the mouse model of breast cancer, and the report did not mention any activity of 1-MNA or 1,4-DMP in other types of malignant tumors or with different anticancer agents.

In the present work, we investigated the activity of both compounds in the model of TRAMP mice that spontaneously develop prostate tumors. Similar to our previously reported studies [21], both compounds, when administrated alone to mice developing prostate tumors, revealed no significant anticancer activity; however, to some extent these compounds delayed the disease onset (Fig. 1a-c).
Such a delayed disease onset might be attributed to the prostacyclin-dependent activity of the compounds, as prostacyclin was shown to inhibit lung tumor development in PPAR $\gamma$-dependent mechanism [31] that was also shown to be involved in tumor growth arrest in prostate tumors [32,33]. Lack of the significant tumor preventing activity of both pyridine compounds while being somehow disappointing in terms of the possible application of 1MNA, and its analog in the prevention of prostate cancer, is important for their implementation in anticancer treatments, in general, as once again we demonstrated that neither 1-MNA nor 1,4-DMP promoted the growth of solid tumors. On the contrary, we have not observed any antimetastatic activity of neither of the studied compounds. In contrast, among 1-MNA-treated animals, we even observed a slight increase of metastases frequency (Fig. 1c and d). Such a surprising result might be the consequence of prostacyclin-related inhibition of natural killer cells [34] that, in turn, was shown to stimulate prostate tumor metastasis [35]. Another explanation of the observed limited antimetastatic activity of both 1-MNA and 1,4-DMP might be associated with previously reported relationship between thrombin generation and the growth and metastasis of prostate tumors in TRAMP mice [36]. Possibly, thrombin as a potent coagulation and platelet activator that was proven to facilitate metastasis [37] counteracts a possible antiplatelet activity of pyridine compounds in this model. Importantly, in this study, we noted that during the prostate tumor development, TGF$\beta 1$ plasma concentration in TRAMP mice increased (Fig. 1p), which remains consistent with the previous reports indicating the usefulness of this molecule as a prognostic factor in prostate tumors [38].

When investigating the anticancer activity of therapeutic regimen including simultaneous use of docetaxel and 1,4DMP (that seemed to be more potent in the model of prostate tumor as compared with 1-MNA) in the therapy of metastatic human prostate cancer PC-3M-luc2, we observed $60 \%$ enhancement of the antitumor activity of docetaxel given alone (Fig. 2c) and complete abolition of metastases formation (Table 3) in mice treated with docetaxel administrated with 1,4-DMP. These results confirm that 1,4-DMP may promote anticancer activity of various cytotoxic drugs. Beneficial therapy outcome was also reflected in the decreased plasma level of TGF $\beta-1$, a molecule often acknowledged as a prognostic marker in prostate cancer (Fig. 2i).

TGF- $\beta 1$ is commonly recognized as a molecule inducing epithelial-to-mesenchymal transition (EMT) in tumorforming cells. EMT is a phenomenon in result of which non-invasive tumor cells of epithelial phenotype acquire mesenchymal properties and become able to migrate and invade distant tissues [39]. Therefore, in our study, lower plasma concentration of TGF- $\beta 1$, and by implication lower 
metastatic capacity, was associated with higher expression ratio of E-cadherin to $\mathrm{N}$-cadherin (Fig. 2f), cell adhesion molecules commonly accepted as important markers of EMT in cancer cells, including those of prostate origin [40]. Lower metastatic capacity of tumor-forming cells was additionally accompanied by the lower level of short Ecadherin fragments $(40 \mathrm{kDa})$ observed in the tumor mass of mice lacking metastases. Such short intracellular protein fragments arise because of full-length E-cadherin cleavage resulting in the release into extracellular matrix and next to bloodstream of $80 \mathrm{kDa}$ E-cadherin extracellular domain [41]. Indeed, $80 \mathrm{kDa}$ fragments identified in metastatic sites or serum were previously discussed as potential prostate cancer progression markers [42, 43]. Accordingly, in our study, we observed that $40 \mathrm{kDa}$ intracellular domain of Ecadherin was abundant in tumor mass isolated from mice bearing PC-3M-luc2 tumors diagnosed with metastases (Fig. 2g). Finally, the prominent efficacy of the combined treatment comprising the use of docetaxel and 1,4-DMP is additionally confirmed by the decreased expression of VEGFR-1 (Fig. 2h), another prognostic marker that has been previously linked to enhanced metastatic potential of prostate tumors [44].

We have previously shown that observed enhanced antitumor and antimetastatic activity of cytotoxic drugs when in a combination with 1,4-DMP might be a result of antiplatelet activity of the latter compound [21]. Platelets, in turn, contribute to metastases formation by several mechanisms as comprehensively reviewed in the literature [45, 46]. To confirm that increased anticancer efficacy of docetaxel observed when cytotoxic drug was given with 1,4DMP was associated with diminished platelets activity, we have analyzed morphological and biochemical parameters reflecting platelet activation status. In this regard, in mice receiving the studied combined treatment, we observed lowered values of mean platelet volume and PDW (Fig. 3a-d) that may suggest decreased platelet activity [47, 48]. Additionally, in mice treated with docetaxel and 1,4-DMP, we also noted a marked reduction in plasma concentrations of $\mathrm{TXB}_{2}, \mathrm{vWF}$ and soluble P-selectin (Fig. 3e-h), constituting biochemical markers, further confirming diminished platelet activity.

Interestingly, increased antitumor activity of docetaxel when administrated simultaneously with 1,4-DMP was accompanied by its reduced toxicity manifested in the decreased incidence of treatment-related deaths and improved liver function (Fig. 4). Although we are currently investigating these phenomena, our initial results indicate that the observed protective activity of 1,4-DMP may involve acetylcholinesterase and consequently histamine-dependent pathways. It seems possible that in response to the treatment with 1,4-DMP, the level of histamine is increased that, in turn, may prevent liver injury [49]. This novel and unexpected feature of the 1,4-DMP treatment might not only be of a great value for possible improvement of side effects in patients undergoing chemotherapy, but may also allow to increase dosages in patients with drug-resistant tumors to induce desired response while maintaining acceptable treatment toxicity.

\section{Conclusions}

The results of the presented study prove that neither 1MNA nor 1,4-DMP when administrated alone do not influence the development and growth of the primary prostate tumors supporting our previous findings in the murine model of metastatic breast cancer. However, pyridine compounds, such as 1,4-DMP, may beneficially influence the antitumor and antimetastatic activity of docetaxel and additionally limit the side effects accompanying chemotherapy. Such findings allow us to believe that pyridine compound endowed with $\mathrm{PGI}_{2}$ releasing properties $[18,20]$ may become a promising agent for the adjuvant therapy of metastatic cancer.

\section{Additional file}

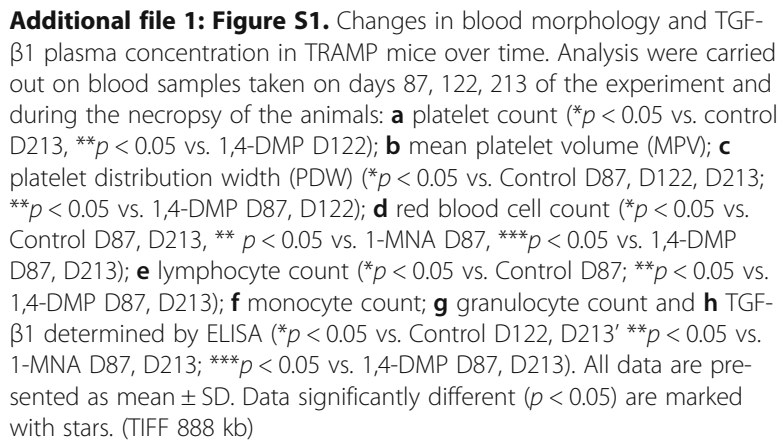

Additional file 1: Figure S1. Changes in blood morphology and TGF$\beta 1$ plasma concentration in TRAMP mice over time. Analysis were carried out on blood samples taken on days 87, 122, 213 of the experiment and during the necropsy of the animals: a platelet count $\left({ }^{*} p<0.05\right.$ vs. control D213, ${ }^{* *} p<0.05$ vs. 1,4-DMP D122); b mean platelet volume (MPV); c platelet distribution width (PDW) $\left({ }^{*} p<0.05\right.$ vs. Control D87, D122, D213; ${ }^{* *} p<0.05$ vs. 1,4-DMP D87, D122); $\mathbf{d}$ red blood cell count ${ }^{*} p<0.05$ vs. Control D87, D213, ${ }^{* *} p<0.05$ vs. $1-M N A$ D87, ${ }^{* * *} p<0.05$ vs. 1,4-DMP D87, D213); e lymphocyte count $\left({ }^{*} p<0.05\right.$ vs. Control D87; ${ }^{* *} p<0.05$ vs. 1,4-DMP D87, D213); f monocyte count; $\mathbf{g}$ granulocyte count and $\mathbf{h}$ TGF$\beta 1$ determined by ELISA ( ${ }^{*} p<0.05$ vs. Control D122, D213'*** $p<0.05$ vs. 1-MNA D87, D213; ${ }^{* * *} p<0.05$ vs. 1,4-DMP D87, D213). All data are presented as mean \pm SD. Data significantly different $(p<0.05)$ are marked with stars. (TIFF $888 \mathrm{~kb}$ )

\section{Abbreviations}

\%BW: \% of body weight; 1,4-DMP: 1,4- dimethylpyridine; 1-MNA: 1methylnicotinamide; 6-keto-PGF1a: 6-keto-prostaglandin F1a; a.u.: Arbitrary units; ALT: Alanine aminotransferase; AST: Aspartate aminotransferase; DTX: Docetaxel; EDTA: Ethylenediaminetetraacetic acid; EMT: Epithelial to mesenchymal transition; HBSS: Hanks Balanced Salt Solution; LDH: Lactate dehydrogenase; MPV: Mean platelet volume; NA: Nicotinamide; NNMT: Nicotinamide N-methyltransferase; PCT: Platelet crit; PDW: Platelet distribution width; $\mathrm{PGI}_{2}$ : Prostacyclin; PVDF: Polyvinylidene fluoride; RBC: Red blood cells; rpm: Round per minute; SD: Standard deviation; SDS: Sodium dodecyl sulfate; TGF- $\beta 1$ : Transforming growth factor $\beta 1$; TGl: Tumor growth inhibition; TNF-a: Tumor necrosis factor $\alpha_{;}$TV: Tumor volume;

$\mathrm{TXB}_{2}$ : Thromboxane $\mathrm{B}_{2}$; VEGFR-1: Vascular endothelial growth factor receptor 1; vWF: von Willebrand Factor

\section{Acknowledgements}

Not applicable.

\section{Funding}

This study was supported by the European Union from the resources of the European Regional Development Fund within the Innovative Economy Program (grant coordinated by the JCET-UJ, No. POIG.01.01.02-00-069/09) and The National Center for Research and Development under the Polish Strategic Framework Program STRATEGMED (grant coordinated by JCET-UJ No. STRATEGMED1/233226/11/NCBR/2015). The publication was supported 
by Wroclaw Center of Biotechnology within a Program The Leading National Research Center (KNOW) for years 2014-2018.

The funding bodies did not participate in the design of the study and collection, analysis and interpretation of data and in writing the manuscript.

\section{Availability of data and materials}

All data generated or analyzed during this study are included in this published article [and its supplementary information files].

\section{Authors' contributions}

$A D$, JW and SC conceived and designed the experiments; $A M$ and JG synthetized and provided pyridinium salts; AD, JW, MS, MM and MN performed the experiments; $A D$ analyzed the data and wrote the paper. All authors read and approved the final manuscript.

\section{Competing interest}

The authors declare that they have no competing interests.

\section{Consent for publication}

Not applicable.

\section{Ethics approval and consent to participate}

All animal experiments were performed according to the Interdisciplinary Principles and Guidelines for the Use of Animals in Research, Marketing and Education issued by the New York Academy of Sciences' Ad Hoc Committee on Animal Research and were approved by the 1st Local Committee for Experiments with the Use of Laboratory Animals, Wroclaw, Poland.

\section{Author details}

${ }^{1}$ Hirszfeld Institute of Immunology and Experimental Therapy, Polish Academy of Sciences, Weigla 12, Wroclaw 53-114, Poland. ${ }^{2}$ Wroclaw University of Environmental and Life Sciences, Norwida 31, Wroclaw 50-375, Poland. ${ }^{3}$ Chair of Pharmacology, Jagiellonian University, Medical College, Grzegorzecka 16, Krakow 31-531, Poland. ${ }^{4}$ Jagiellonian Center for Experimental Therapeutics (JCET), Jagiellonian University, Bobrzynskiego 14, Krakow 30-348, Poland. 'Lodz University of Technology, Zeromskiego 116, Lodz 90-924, Poland.

\section{Received: 9 November 2016 Accepted: 1 March 2017} Published online: 07 March 2017

\section{References}

1. Torre LA, Bray F, Siegel RL, Ferlay J, Lortet-Tieulent J, Jemal A. Global cancer statistics, 2012. CA Cancer J Clin. 2015;65:87-108.

2. Cuzick J, Thorat MA, Andriole G, Brawley OW, Brown PH, Culig Z, Eeles RA, Ford LG, Hamdy FC, Holmberg L, et al. Prevention and early detection of prostate cancer. Lancet Oncol. 2014;15:e484-92.

3. Hwang C. Overcoming docetaxel resistance in prostate cancer: a perspective review. Ther Adv Med Oncol. 2012:4:329-40.

4. Herbst RS, Khuri FR. Mode of action of docetaxel - a basis for combination with novel anticancer agents. Cancer Treat Rev. 2003;29:407-15.

5. Pienta KJ. Preclinical mechanisms of action of docetaxel and docetaxel combinations in prostate cancer. Semin Oncol. 2001;28:3-7.

6. Tannock I, Gospodarowicz M, Meakin W, Panzarella T, Stewart L, Rider W. Treatment of metastatic prostatic cancer with low-dose prednisone: evaluation of pain and quality of life as pragmatic indices of response. J Clin Oncol. 1989;7:590-7.

7. Herr I, Pfitzenmaier J. Glucocorticoid use in prostate cancer and other solid tumours: implications for effectiveness of cytotoxic treatment and metastases. Lancet Oncol. 2006;7:425-30.

8. Fakih M, Johnson CS, Trump DL. Glucocorticoids and treatment of prostate cancer: a preclinical and clinical review. Urology. 2002;60:553-61.

9. Sartor O, Weinberger M, Moore A, Li A, Figg WD. Effect of prednisone on prostate-specific antigen in patients with hormone-refractory prostate cancer. Urology. 1998;52:252-6.

10. Teply BA, Luber B, Denmeade SR, Antonarakis ES. The influence of prednisone on the efficacy of docetaxel in men with metastatic castrationresistant prostate cancer. Prostate Cancer Prostatic Dis. 2016;19:72-8.

11. Geifman N, Butte AJ. A patient-level data meta-analysis of standard-of-care treatments from eight prostate cancer clinical trials. Sci Data. 2016;3:160027.
12. Hotte SJ, Saad F. Current management of castrate-resistant prostate cancer. Curr Oncol. 2010;17 Suppl 2:S72-79.

13. Tannock IF, de Wit R, Berry WR, Horti J, Pluzanska A, Chi KN, Oudard S, Theodore C, James ND, Turesson I, et al. Docetaxel plus prednisone or mitoxantrone plus prednisone for advanced prostate cancer. N Engl J Med. 2004;351:1502-12.

14. Lam ET, Flaig TW. Upfront chemotherapy for metastatic prostate cancer. Oncology. 2015;29:956. Williston Park.

15. Dorff TB, Crawford ED. Management and challenges of corticosteroid therapy in men with metastatic castrate-resistant prostate cancer. Ann Oncol. 2013;24:31-8

16. Zhang C, Wenger T, Mattern J, llea S, Frey C, Gutwein P, Altevogt $P$, Bodenmuller W, Gassler N, Schnabel PA, et al. Clinical and mechanistic aspects of glucocorticoid-induced chemotherapy resistance in the majority of solid tumors. Cancer Biol Ther. 2007;6:278-87.

17. Gebicki J, Sysa-Jedrzejowska A, Adamus J, Wozniacka A, Rybak M, Zielonka J. 1-Methylnicotinamide: a potent anti-inflammatory agent of vitamin origin. Pol J Pharmacol. 2003:55:109-12.

18. Chlopicki S, Swies J, Mogielnicki A, Buczko W, Bartus M, Lomnicka M, Adamus J, Gebicki J. 1-Methylnicotinamide (MNA), a primary metabolite of nicotinamide, exerts anti-thrombotic activity mediated by a cyclooxygenase-2/prostacyclin pathway. Br J Pharmacol. 2007;152:230-9.

19. Bryniarski K, Biedron R, Jakubowski A, Chlopicki S, Marcinkiewicz J. Antiinflammatory effect of 1-methylnicotinamide in contact hypersensitivity to oxazolone in mice; involvement of prostacyclin. Eur J Pharmacol. 2008:578:332-8.

20. Kalaska B, Piotrowski L, Leszczynska A, Michalowski B, Kramkowski K, Kaminski T, Adamus J, Marcinek A, Gebicki J, Mogielnicki A, Buczko W. Antithrombotic effects of pyridinium compounds formed from trigonelline upon coffee roasting. J Agric Food Chem. 2014;62:2853-60.

21. Blazejczyk A, Switalska M, Chlopicki S, Marcinek A, Gebicki J, Nowak M, Nasulewicz-Goldeman A, Wietrzyk J. 1-methylnicotinamide and its structural analog 1,4-dimethylpyridine for the prevention of cancer metastasis. J Exp Clin Cancer Res. 2016;35:110

22. Milczarek M, Filip-Psurska B, Swietnicki W, Kutner A, Wietrzyk J. Vitamin D analogs combined with 5-fluorouracil in human HT-29 colon cancer treatment. Oncol Rep. 2014:32:491-504.

23. Noguchi K, Matsuzaki T, Ojiri Y, Sakanashi M, Nakasone J, Sakanashi M. Prostacyclin causes splenic dilation and haematological change in dogs. Clin Exp Pharmacol Physiol. 2006;33:81-8.

24. Alston TA, Abeles RH. Substrate specificity of nicotinamide methyltransferase isolated from porcine liver. Arch Biochem Biophys. 1988;260:601-8.

25. Yu T, Wang YT, Chen P, Li YH, Chen YX, Zeng H, Yu AM, Huang M, Bi HC. Effects of nicotinamide N-methyltransferase on PANC-1 cells proliferation, metastatic potential and survival under metabolic stress. Cell Physiol Biochem. 2015;35:710-21.

26. Zhang J, Wang Y, Li G, Yu H, Xie X. Down-regulation of nicotinamide Nmethyltransferase induces apoptosis in human breast cancer cells via the mitochondria-mediated pathway. PLoS One. 2014;9:e89202.

27. Chen C, Wang X, Huang X, Yong H, Shen J, Tang Q, Zhu J, Ni J, Feng Z Nicotinamide $\mathrm{N}$-methyltransferase: a potential biomarker for worse prognosis in gastric carcinoma. Am J Cancer Res. 2016;6:649-63.

28. Parsons RB, Aravindan S, Kadampeswaran A, Evans EA, Sandhu KK, Levy ER, Thomas MG, Austen BM, Ramsden DB. The expression of nicotinamide Nmethyltransferase increases ATP synthesis and protects SH-SY5Y neuroblastoma cells against the toxicity of Complex I inhibitors. Biochem J. 2011:436:145-55.

29. Zhou W, Gui M, Zhu M, Long Z, Huang L, Zhou J, He L, Zhong K. Nicotinamide $\mathrm{N}$-methyltransferase is overexpressed in prostate cancer and correlates with prolonged progression-free and overall survival times. Oncol Lett. 2014;8:1175-80.

30. Sartini D, Santarelli A, Rossi V, Goteri G, Rubini C, Ciavarella D, Lo Muzio L, Emanuelli M. Nicotinamide N-methyltransferase upregulation inversely correlates with lymph node metastasis in oral squamous cell carcinoma. Mol Med. 2007:13:415-21.

31. Nemenoff R, Meyer AM, Hudish TM, Mozer AB, Snee A, Narumiya S, Stearman RS, Winn RA, Weiser-Evans M, Geraci MW, Keith RL. Prostacyclin prevents murine lung cancer independent of the membrane receptor by activation of peroxisomal proliferator-activated receptor gamma. Cancer Prev Res. 2008;1:349-56. Phila.

32. Subbarayan V, Sabichi AL, Kim J, Llansa N, Logothetis CJ, Lippman SM, Menter DG. Differential peroxisome proliferator-activated receptor-gamma isoform expression and agonist effects in normal and malignant prostate cells. Cancer Epidemiol Biomarkers Prev. 2004;13:1710-6. 
33. Sikka S, Chen L, Sethi G, Kumar AP. Targeting PPARgamma signaling cascade for the prevention and treatment of prostate cancer. PPAR Res. 2012;2012:968040.

34. Lanefelt $F$, Ullberg $M$, Jondal $M$, Fredholm BB. PGE1 and prostacyclin suppression of NK-cell mediated cytotoxicity and its relation to cyclic AMP. Med Biol. 1983;61:324-30.

35. Liu G, Lu S, Wang X, Page ST, Higano CS, Plymate SR, Greenberg NM, Sun S, $\mathrm{Li}$ Z, Wu JD. Perturbation of NK cell peripheral homeostasis accelerates prostate carcinoma metastasis. J Clin Invest. 2013;123:4410-22.

36. Hu L, Ibrahim S, Liu C, Skaar J, Pagano M, Karpatkin S. Thrombin induces tumor cell cycle activation and spontaneous growth by down-regulation of p27(Kip1), in association with the Up-regulation of Skp2 and MiR-222. Cancer Res. 2009;69:3374-81.

37. Nierodzik ML, Kajumo F, Karpatkin S. Effect of thrombin treatment of tumor cells on adhesion of tumor cells to platelets in vitro and tumor metastasis in vivo. Cancer Res. 1992;52:3267-72.

38. Adler HL, McCurdy MA, Kattan MW, Timme TL, Scardino PT, Thompson TC. Elevated levels of circulating interleukin- 6 and transforming growth factorbeta1 in patients with metastatic prostatic carcinoma. J Urol. 1999;161:182-7.

39. Moustakas A, Heldin CH. Mechanisms of TGFbeta-Induced EpithelialMesenchymal Transition. J Clin Med. 2016;5(7):63.

40. Huo C, Kao YH, Chuu CP. Androgen receptor inhibits epithelialmesenchymal transition, migration, and invasion of PC-3 prostate cancer cells. Cancer Lett. 2015;369:103-11.

41. David JM, Rajasekaran AK. Dishonorable discharge: the oncogenic roles of cleaved E-cadherin fragments. Cancer Res. 2012;72:2917-23.

42. Kuefer R, Hofer MD, Zorn CSM, Engel O, Volkmer BG, Juarez-Brito MA, Eggel M, Gschwend JE, Rubin MA, Day ML. Assessment of a fragment of ecadherin as a serum biomarker with predictive value for prostate cancer. $\mathrm{Br}$ J Cancer. 2005:92:2018-23.

43. Kuefer R, Hofer MD, Gschwend JE, Pienta KJ, Sanda MG, Chinnaiyan AM, Rubin MA, Day ML. The role of an $80 \mathrm{kDa}$ fragment of E-cadherin in the metastatic progression of prostate cancer. Clin Cancer Res. 2003;9:6447-52.

44. Tsourlakis MC, Khosrawi P, Weigand P, Kluth M, Hube-Magg C, Minner S, Koop C, Graefen M, Heinzer H, Wittmer C, et al. VEGFR-1 overexpression identifies a small subgroup of aggressive prostate cancers in patients treated by prostatectomy. Int J Mol Sci. 2015;16:8591-606.

45. Blazejczyk A, Papiernik D, Porshneva K, Sadowska J, Wietrzyk J. Endothelium and cancer metastasis: perspectives for antimetastatic therapy. Pharmacol Rep. 2015;67:711-8.

46. Leblanc R, Peyruchaud O. Metastasis: new functional implications of platelets and megakaryocytes. Blood. 2016;128:24-31.

47. Chu SG, Becker RC, Berger PB, Bhatt DL, Eikelboom JW, Konkle B, Mohler ER, Reilly MP, Berger JS. Mean platelet volume as a predictor of cardiovascular risk: a systematic review and meta-analysis. J Thromb Haemost. 2010;8:148-56.

48. Vagdatli E, Gounari E, Lazaridou E, Katsibourlia E, Tsikopoulou F, Labrianou I. Platelet distribution width: a simple, practical and specific marker of activation of coagulation. Hippokratia. 2010;14:28-32.

49. Masaki T, Chiba S, Tatsukawa H, Noguchi H, Kakuma T, Endo M, Seike M, Watanabe $\mathrm{T}$, Yoshimatsu $\mathrm{H}$. The role of histamine $\mathrm{H} 1$ receptor and $\mathrm{H} 2$ receptor in LPS-induced liver injury. FASEB J. 2005;19:1245-52.

\section{Submit your next manuscript to BioMed Central and we will help you at every step:}

- We accept pre-submission inquiries

- Our selector tool helps you to find the most relevant journal

- We provide round the clock customer support

- Convenient online submission

- Thorough peer review

- Inclusion in PubMed and all major indexing services

- Maximum visibility for your research

Submit your manuscript at www.biomedcentral.com/submit
Biomed Central 